\title{
PDA stenting in 6-month-old infant with suprasystemic pulmonary hypertension as a treatment option for hypertensive crisis
}

\author{
Joanna Płużańska, Katarzyna Ostrowska, Jadwiga Moll, Paweł Dryżek, Tomasz Moszura \\ Department of Paediatric Cardiology, Polish Mother's Memorial Institute, Lodz, Poland
}

Adv Interv Cardiol 2019; 15, 3 (57): 371-373

DOI: https://doi.org/10.5114/aic.2019.87898

\section{Introduction}

Pulmonary arterial hypertension is a severe disease with limited therapeutic options. When pharmacological treatment for children under 1 year is insufficient, surgical palliative options include the Potts shunt, creating an interatrial connection and interventional PDA stenting.

\section{Aim}

We present a case of a 6-month-old patient with suprasystemic pulmonary hypertension in whom we implanted a stent into the residual persistent arterial duct allowing decompression of the right ventricle and clinical stabilization.

\section{Case report}

A 6-month-old patient weighing $5.5 \mathrm{~kg}$ was admitted to the Pediatric Cardiology Department for cardiac catheterization due to pulmonary hypertension (PH). $\mathrm{PH}$ was diagnosed at 2 months and oral medication was started. Regular outpatient monitoring showed failure to thrive, progression of echocardiographic changes with growing disproportion between ventricles due to right ventricle dilatation, and rising NTproBNP levels $(4214 \mathrm{pg} / \mathrm{ml}$ to $8111 \mathrm{pg} / \mathrm{ml}$ before intervention).

Echocardiographic examination upon admission showed an enlarged right ventricle with hyperkinetic interventricular septum, residual $0.5-1 \mathrm{~mm}$ patent ductus arteriosus (PDA) shunting right-left with pressure gradient $55 \mathrm{~mm} \mathrm{Hg}$, small foramen ovale with no visible shunting across the interatrial septum, dilated right ventricle, borderline diameter of the mitral valve, aortic valve and compressed left ventricle (Figure 1). During hospital- ization due to rapid deterioration of the patient's condition, poor response to oral medication (maximum dose of sildenafil), and progressing signs of low cardiac output we decided on urgent cardiac catheterization with implantation of a stent into the patent ductus arteriosus to minimize the risk of pulmonary hypertensive crisis.

We prepared an appropriate anesthetic management plan and were ready to treat pulmonary hypertensive crisis if it occurred during intervention. After initiation of general anesthesia cardiac catheterization was performed through the femoral vein and artery, and pressure measurements were taken in the right atrium, right ventricle and pulmonary artery. Pulmonary wedge pressure was assessed. The catheter was then threaded through the small patent foramen ovale (PFO) allowing the measurement of pressures in the left atrium and ventricle. Taking into account all measurements pulmonary hypertension was confirmed (Figure 2). After passing coronary guidewire 0.014 soft through $1 \mathrm{~mm}$ residual PDA preimplantation angioplasty was performed with an Advance balloon $3.5 \times 16 \mathrm{~mm}$. We implanted a coronary stent into the PDA. Because of distal migration a second stent needed to be added, widening the duct to $4.3 \mathrm{~mm}$, achieving unrestrictive flow with no signs of coarctation. Pulmonary valve pressures instantly dropped to systemic pressures and follow-up echocardiography showed smaller disproportion between ventricles, normalization of mitral and aortic diameters and left-to-right shunting across the foramen ovale (Figure 1). The patient showed rapid clinical improvement, decrease in NTproBNP level $(1780 \mathrm{pg} / \mathrm{ml})$ and was discharged 7 days after the intervention. Three months after the intervention the patient is stable and thriving, progressing in development with NTproBNP level $689 \mathrm{pg} / \mathrm{ml}$. Genetic testing confirmed

\section{Corresponding author:}

Joanna Płużańska, Department of Paediatric Cardiology, Polish Mother’s Memorial Institute, 281/289 Rzgowska St, $93-338$ Lodz, Poland, phone: +48 537909 702, e-mail: asia.pluzanska@yahoo.com

Received: 7.11.2018, accepted: 1.04.2019. 

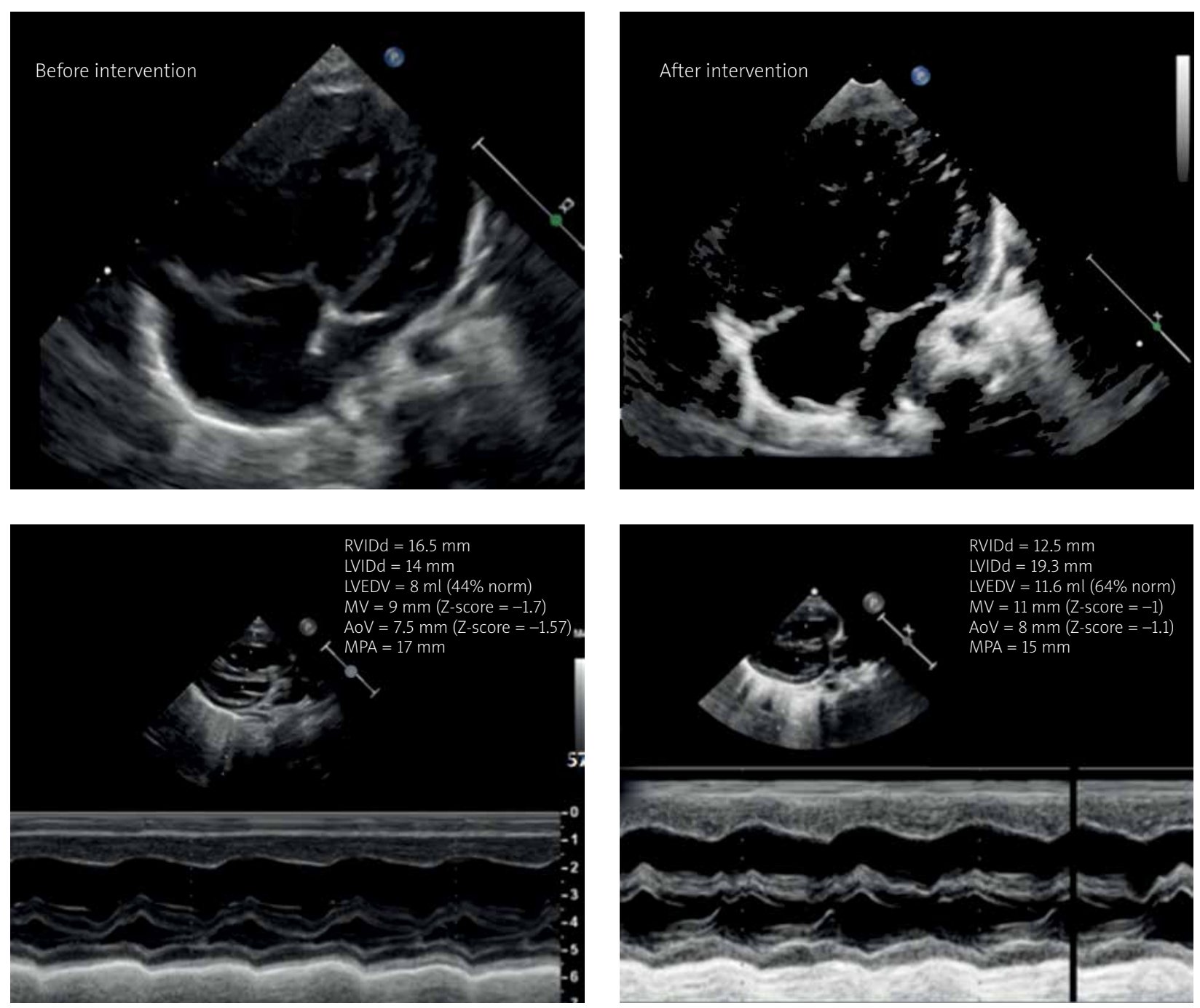

Figure 1. Comparison of echocardiographic images before and after intervention
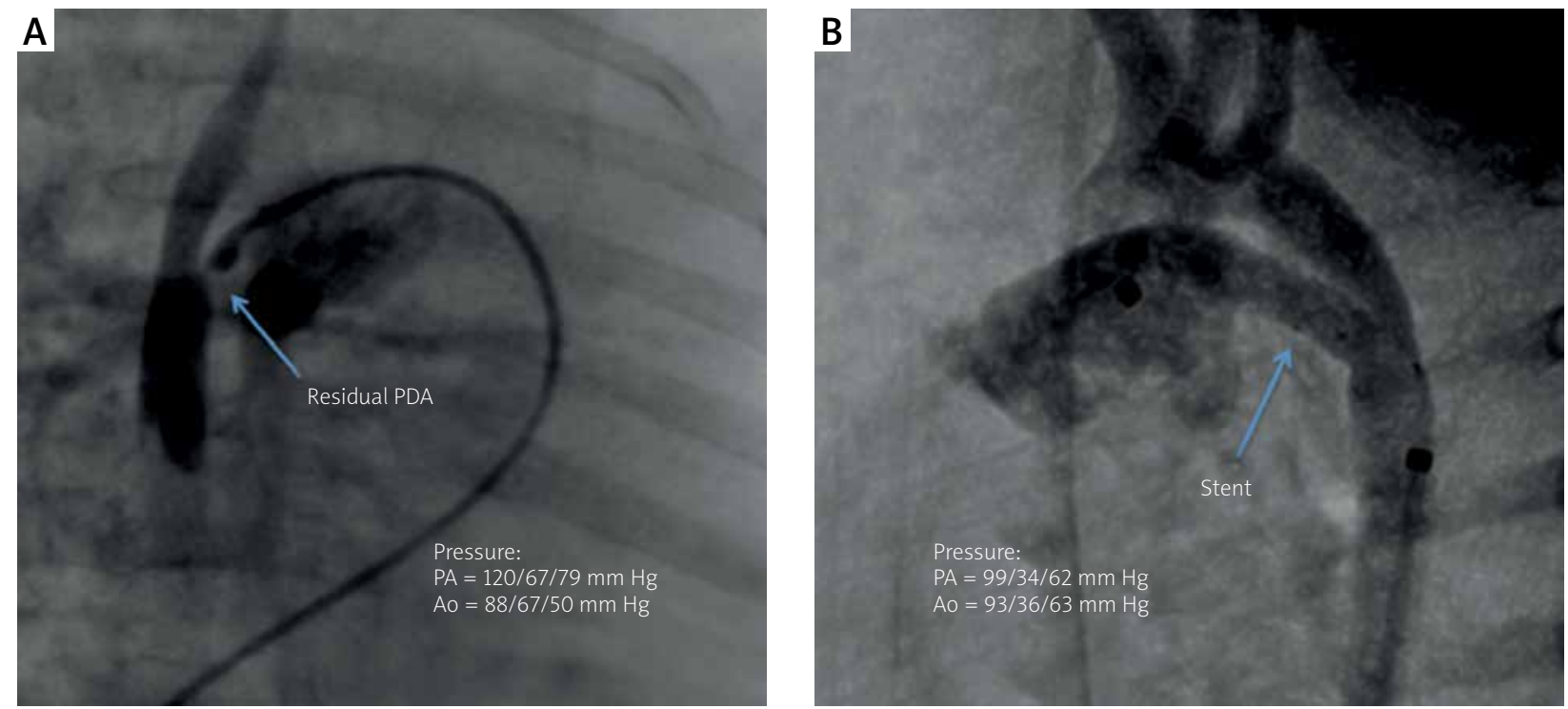

Figure 2. Images from cardiac intervention with pressure measurements. A - Residual PDA, pressures prior to intervention, B - coronary stents expanded to $4.3 \mathrm{~mm}$, post-intervention pressure measurements 
microdeletion in chromosome 17 (17q22q23.2 encompassing TBX2 and TBX4 genes).

\section{Discussion}

Pulmonary arterial hypertension is a severe disease with limited therapeutic options, especially in children under 1 year of age. The prognosis is poor with a high mortality rate and risk of sudden death. Only sildenafil therapy is available for children under 24-months of age [1-3]. Palliative treatment options include surgical or interventional creation of the Potts shunt as a means of generating Eisenmenger physiology as a bridge to heartlung transplant [4]. Atrial septostomy is also possible, but the procedure was not the method of choice in this case [5], as illustrated by our patient in whom a $3 \mathrm{~mm}$ foramen ovale was inadequate for decompression. For many patients heart-lung transplant is the only treatment, but donors are scarce in Poland especially for infants [6].

Cardiac catheterization is high risk in infants with $\mathrm{PH}$ and requires a specific anesthetic management plan with secured inhaled nitric oxide and epoprostenol in the catheterization laboratory [7, 8]. This case presents urgent palliative PDA stenting in a 6-month-old patient with suprasystemic pulmonary hypertension on the verge of hypertensive crisis [8].

This case shows that patent ductal stenting in small infants is possible and a good palliative option. It allows for the decompression of suprasystemic pulmonary pressure resulting in immediate clinical and hemodynamic improvement until other treatment options become available.

\section{Conflict of interest}

The authors declare no conflict of interest.

\section{References}

1. Galiè N, Humbert M, Vachiery JL, et al. Wytyczne ESC/ERS dotyczące rozpoznawania i leczenia nadciśnienia płucnego w 2015 roku. Kardiol Pol 2015; 73: 1127-206.

2. Abman SH, Hansmann G, Archer SL, et al. Pediatric pulmonary hypertension. Circulation 2015; 132: 2037-99.

3. Ploegstra MJ, Douwes JM, Roofthooft MTR, et al. Identification of treatment goals in paediatric pulmonary arterial hypertension. Eur Respir J 2014; 44: 1616-26.

4. Baruteau AE, Serraf A, Lévy M, et al. Potts shunt in children with idiopathic pulmonary arterial hypertension: long-term results. Ann Thorac Surg 2012; 94: 817-24.

5. Micheletti A, Hislop AA, Lammers A, et al. Role of atrial septostomy in the treatment of children with pulmonary arterial hypertension. Heart 2006; 92: 969-72.

6. Goldstein BS, Sweet SC, Mao J, et al. Lung transplantation in children with idiopathic pulmonary arterial hypertension: an 18-year experience. J Heart Lung Transplant 2011; 30: 1148-52.

7. D’Alto M, Santoro G, Palladino M, et al. Patent ductus arteriosus stenting for palliation of severe pulmonary arterial hypertension in childhood. Cardiol Young 2015; 25: 350-4.
8. Friesen RH, Williams GD. Anesthetic management of children with pulmonary arterial hypertension. Pediatr Anesth 2008; 18: 208-16. 